
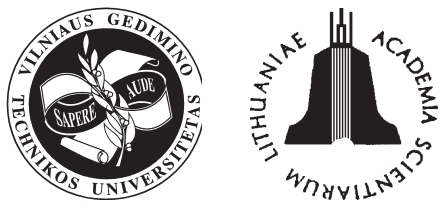

ISSN 1648-4142 print / ISSN 1648-3480 online TRANSPORT

www.transport.vtu.lt

\title{
USE OF AN EXPENDITURE REDUCING MODEL IN RAILWAY CARRIAGE
}

\author{
Olga Lingaitien $\dot{e}^{1}$, Vytautas Lingaitis ${ }^{2}$ \\ Vilnius Gediminas Technical University, \\ ${ }^{1}$ Faculty of Transport Engineering, Department of Transport Management, Plytinès g. 27, \\ LT-10105 Vilnius, Lithuania.Phone: (+370 5)2744797,E-mail private14@takas.lt \\ ${ }^{2}$ Faculty of Business Management, Department of Finance Enginering, Sauletekio al. 11, \\ LT-10223 Vilnius, Lithuania.E-mail: vytautas.lingaitis@lra.lt
}

Received 1 December 2005; accepted 4 January 2006

\begin{abstract}
Passenger transportation by railway is fast, safe, convenient and affordable for people, but it is usually not profitable for the state. Therefore, making passenger transportation profitable is a task of vital importance. Various calculations are used to optimize this process.

The paper considers the problems of economical passenger transportation which may by described by two models: the first model is based on the assessment of income-expenses of separate services, while the second model is related to the assessment of expenses according to their types.
\end{abstract}

Keywords: income, expenses, reduce, model.

\section{Introduction}

One of the most important problems associated with railway transport in Europe is associated with losses experienced by passenger carriers. Now, only long international routes are profitable, while railway companies and carriers operating on local routes experience losses. The agreements between the companies providing transport services in particular regions and the authorities about the financial support of carriers experiencing losses on particular routes could help resolve this problem. The conditions of the above agreements may vary depending on the losses experienced by the companies on particular routes. Both profitable and unprofitable routes should be purchased in bidding. This could provide railway companies with a stimulus to search for reserves allowing them to reduce expenses. State control is needed to ensure that prices are not lowered at the expense of safety. The requirements for safety in transportation should be harmonized in various countries. The problem of passenger safety should be one of top priority in transport.

To attract the flows of passengers to railway transport, the conditions of travel should be considerably improved. Passengers are interested in fast, safe and comfortable transportation at a reasonable cost. If changes are to be made, the schedules of various means of transport should be matched. Usually, rail- way schedules are matched with road transport schedules, however, higher flexibility is required from the railway transport as far as making up of trains and their schedules is concerned.

Tariff policy should also be flexible, with the cost corresponding to the value of provided services. For example, business class passengers are mainly interested in trip duration and comfortability, while the cost is not so important for them. However, holidaymakers should be offered lower prices along with acceptable speed and a comfortability level because, otherwise, they will choose road transport providing cheaper though not so good services.

In considering the costs of passenger transportation by railway it is important not only to know the types of income and expenses but also to determine the weight of these types of expenses. This would allow us to take the appropriate actions aimed to reduce expenses and to increase profit.

\section{A model of determining the relationship between income and expenses depending on a particular unit, department or service}

Income and expenses of passenger transportation with respect to a particular unit may be determined by the following model [1]:

$$
\Delta=\sum I_{\text {inc }}+\sum E_{\text {exp }}, \text { EUR, }
$$


where $\sum I_{i n c}$ - total income obtained from passenger transportation, Lt; $\sum E_{\text {exp }}-$ overall expenses, Lt.

The income will consist of [2]:

$$
\sum I_{i n c}=p_{1} I_{l c}+p_{2} I_{i c}, \quad \text { EUR, }
$$

where $I_{l c}$ - income obtained from local transportation, Lt; $I_{i c}$ - income obtained from international transportation, $\mathrm{Lt} ; p_{1}$ ir $p_{2}$-efficient, which estimates value of income.

The expenses will consist of:

$$
\begin{aligned}
\sum E_{\exp }= & n_{1} E_{c}+n_{2} E_{p s}+n_{3} E_{r}+n_{4} E_{a}+ \\
& +n_{5} E_{l}+n_{6} E_{t}+n_{7} E_{c a}+n_{8} E_{b}+ \\
& +n_{9} E_{e s}+n_{10} E_{o}, \quad \mathrm{E} U R
\end{aligned}
$$

where $E_{c}$ - expenses of wagon depot, EUR; $E_{p s}-$ expenses of a unit providing services to passengers, EUR; $E_{r}$ - expenses of road maintenance department, EUR; $E_{a}$ - expenses of automation and communication department, EUR; $E_{l}$ - expenses of locomotive depot, EUR; $E_{t}$ - expenses of traffic organization, EUR; $E_{c a}$ - expenses of the administration department of a company, EUR; $E_{b}-$ expenses of building and engineering equipment unit, EUR; $E_{e s}$ - expenses of power supplying unit, EUR; $E_{O}$ - expenses of other departments and services (e.g. centre of diagnostics, security service, etc.), EUR; $n_{1}, n_{2}, \ldots, n_{10}$ - weight coefficients of particular expenses. Weight coefficients for evaluating various kinds of income are calculated as follows [3]:

$$
\begin{aligned}
& p_{1}=\frac{I_{l c}}{\sum I_{i n c}}, \\
& p_{2}=\frac{I_{i c}}{\sum I_{i n c}} .
\end{aligned}
$$

Weight coefficients for assessing the expenses of particular units, departments or services are calculated in the following way:

$$
\begin{aligned}
& n_{1}=\frac{E_{c}}{\sum E_{\text {exp }}}, \\
& n_{2}=\frac{E_{p s}}{\sum E_{\text {exp }}} \text { etc. }
\end{aligned}
$$

Since the expenses of the particular units vary considerably for local and international routes, the calculations of the expenses by formula 3 are made separately for each type of transportation.

The finite model for evaluating the expenses in passenger transportation will be of the form [3]:

$$
\begin{aligned}
& \Delta=\left(0,28 I_{l c}+0,72 I_{t i c}\right)- \\
& -\left(\begin{array}{l}
0,02 S_{c}^{\prime}+0,12 S_{p s}^{\prime}+0,7 S_{r}^{\prime}+0,05 S_{a}^{\prime}+ \\
0,26 S_{l}^{\prime}+0,1 S_{t}^{\prime}+0,02 S_{c a}^{\prime}+0,02 S_{b}^{\prime}+ \\
+0,06 S_{e s}^{\prime}
\end{array}\right)- \\
& -\left(\begin{array}{l}
0,04 S_{c}^{\prime \prime}+0,07 S_{p s}^{\prime \prime}+0,05 S_{r}^{\prime \prime}+0,01 S_{a}^{\prime \prime}+ \\
0,07 S_{l}^{\prime \prime}+0,02 S_{t}^{\prime \prime}+0,01 S_{c a}^{\prime \prime}+0,01 S_{e s}^{\prime \prime}+ \\
+0,01 S_{o}^{\prime \prime}
\end{array}\right),
\end{aligned}
$$

where $S^{\prime}$ and $S^{\prime \prime}$ are the respective expenses of particular units on local and international routes. The numerical values of weight coefficients are obtained from the data provided by the Lithuanian railways.

As shown by the model of assessing expenses depending on a particular unit, the largest weight in passenger transportation expenses is found for the following departments and services:

- on local routes - the locomotive depot, with the weight of 0,26 ; followed by passenger service department - 0,12; traffic department - 0,1; road maintenance department $-0,07$; automation, communication and power supply $-0,05$ each.

- on international routes - passenger service department and the locomotive depot $-0,07$ each; road maintenance department $-0,05$; wagon depot $-0,04$.

\section{The model of determining the relationship between income and expenses depending on the type of ex- penses}

Income and expenses in passenger transportation may also be assessed according to the type of expenses by the following model:

$$
\Delta=\sum I_{i n c}-\sum E_{\exp },
$$

where $\sum I_{i n c}$ - total income obtained from passenger transportation (by formula 2); $\sum E_{\exp }-$ overall expenses, EUR.

The sum of expenses depending on their types will be [4]:

$$
\begin{aligned}
& \sum E_{\exp t}=c_{1} \sum E_{\exp d i r}+ \\
& +c_{2} \sum E_{\exp i n d i r}+c_{3} \sum E_{\exp a c t},
\end{aligned}
$$

where $E_{\text {exp } d i r}$ - direct expenses, EUR; $E_{\text {exp indir }}-$ indirect (variable) expenses, EUR; $E_{\exp \text { act }}-$ operational expenses, EUR; $c_{1}, c_{2}, c_{3}$ - weight coefficients of particular types of expenses. 


$$
\begin{aligned}
& c_{1}=\frac{E_{\exp d i r}}{\sum E_{\exp }}, \\
& c_{2}=\frac{E_{\exp \text { indir }}}{\sum E_{\exp }}, \\
& c_{3}=\frac{E_{\exp a c t}}{\sum E_{\exp }} .
\end{aligned}
$$

Having calculated coefficients $c_{1}, c_{2}, c_{3}$ based on the data provided by the Lithuanian railways, we obtained the following general model of income-expenses [5]:

$$
\begin{aligned}
& \Delta=0,28 I_{l c}+0,72 I_{i c}-0,70 E_{\exp d i r}- \\
& -0,12 E_{\exp i n d i r}-0,18 E_{\exp a c t} .
\end{aligned}
$$

The expenses will consist of:

$$
\begin{aligned}
\sum E_{\exp }= & k_{1} \cdot E_{f c}+k_{2} \cdot E_{w p}+ \\
& +k_{3} \cdot E_{s i}+k_{4} \cdot E_{c r}+ \\
+k_{5} & \cdot E_{m}+k_{6} \cdot E_{d}+k_{7} \cdot E_{o}
\end{aligned},
$$

where $E_{f c}$ - fuel cost, EUR; $E_{w p}$ - work payment, EUR; $E_{s i}-$ social insurance costs, EUR; $E_{c r}-$ capital repair cost, EUR; $E_{m}-$ material costs, EUR; $E_{d}$ - depreciation expenses, EUR; $E_{o}$ - other expenses, EUR; $k_{1}, k_{2}, \ldots, k_{7}$ - weight coefficients of particular expenses.

$$
\begin{aligned}
& \Delta=\left(0,28 P_{v v}+0,72 P_{t v}\right)- \\
& -\left(\begin{array}{l}
0,15 E_{f c}+0,39 E_{w p}+0,14 E_{s i}+ \\
+0,02 E_{c r}+0,06 E_{m}+0,19 E_{d}+ \\
+0,09 E_{o}
\end{array}\right) .
\end{aligned}
$$

Having calculated the values of coefficients $k_{1}$, $k_{2}, k_{3}$ based on the data provided by the Lithuanian railway, we obtained the following income-expenses model (16).

\section{Conclusion}

To reduce the expenses in passenger transportation, the expenses of the locomotive depots (especially on local routes) as well as the expenses of passenger service, traffic and road maintenance departments (on local routes) should be decreased.

As shown by the model (formula 14), the income obtained from international passenger transportation makes the largest part - 0,72, while the income on local routes makes only a third of the total income 0,28 . Direct expenses make 0,70 , i.e. the largest por- tion of overall expenses, followed by operational expenses - 0,18 and indirect (variable) expenses - 0,12.

According to the income-expenses model (formula 16), work payment makes 0,39 , i.e. the largest part of expenses followed by depreciation expenses 0,19 , fuel costs $-0,15$ and social insurance $-0,14$.

The suggested models can be used for assessing the expenses and effectively distributing them among units and departments providing various services as well as for obtaining the maximum profit.

\section{References}

1. Butkevičius, J. Passenger transportation. A monograph. Vilnius: Technika, 2002. 416 p.

2. Butkevičius, J. Investigation methods of passengers carriage freightage of by rail. Transportas (Transport Engineering), Vol XVI, No 3. Vilnius: Technika, 2001, p. VIIXII p. (in Lithuanian).

3. Lingaitis, V.; Lingaitiene, O. Developing Income-Expenses models for railroad passenger transportation. In: TRANSCOM 2005. Žilina, Slovak Republic, 2005, p. 133-137.

4. Kancerevyčius, G. Finances and investment. Kaunas: Smaltija, 2004. 880 p.

5. Vaičiūnas, G. Effective operation of traction rolling stocks on Lithuanian railways. $\mathrm{PhD}$ thesis. Manuscript (Optimalus traukos riedmenu naudojimas Lietuvos geležinkelyje. Daktaro disertacija). Vilnius, 2001. 108 p. (in Lithuanian). 